\title{
Use of SV40 to immunize against hepatitis B surface antigen: implications for the use of SV4O for gene transduction and its use as an immunizing agent
}

\author{
R Kondo, MA Feitelson and DS Strayer \\ Department of Pathology, Anatomy and Cell Biology, Jefferson Medical College, Philadelphia, PA, USA
}

We have described a novel gene transfer system, in which replication-incompetent, $T$ antigen-deleted simian virus-40 (SV40) is used as the transduction vehicle. We report here successful immunization using such an SV40-derived viral vector. Hepatitis $B$ surface antigen (HBsAg) cDNA was cloned downstream of two tandem SV4O early promoters to yield a $T$ antigen-deficient SV40 derivative, SV(HBS). Cultured TC7 cells were exposed to SV(HBS), and expression of HBsAg was detected $24 \mathrm{~h}$ later by Northern blot and RT-PCR analysis. Immunochemistry and Western blot analysis were also performed $24 \mathrm{~h}$ after infection to detect expression of HBsAg. Once it was ascertained that we could express HBsAg in this way, we used SV(HBS) to elicit anti-HBs. SV(HBS) was injected intraperitoneally or subcutaneously into mice every 4 weeks. These mice were bled every 2 weeks and their sera assayed for antibody activity against $\mathrm{HBSAg}$ and SV4O. Production of anti-HBs was measured by ELISA and confirmed by Western blot analysis, both of which demonstrated significant levels of anti-HBs after the second injection. We also tested production of anti-SV4O antibodies by the ability of sera to neutralize SV(HBS) infectivity. We found no evidence of neutralization of SV(HBS) infectivity even after eight inoculations. Thus, replication-incompetent SV4O is itself not a strong antigen. Our data suggest that SV40-based transduction systems may be a useful vehicle for immunization and for other gene transfer applications when a need for multiple inoculations is anticipated.

Keywords: gene transfer; papovavirus; transgene expression

\section{Introduction}

We have reported a novel gene transfer system, in which SV40 is used as a transduction vehicle. ${ }^{1-3}$ SV40 infects resting as well as cycling cells, and is not known to be inactivated by human complement. Its DNA may integrate into the genome of target cells, or it may express its genes episomally, usually as a minichromosome. ${ }^{4} \mathrm{We}$ have found that SV40 can transduce firefly luciferase (luc) activity stably for $>12$ months into murine bone marrow cells in vivo. ${ }^{3}$ We have also shown that SV40-derived vectors can transduce resting human peripheral blood mononuclear cells (PBMC) using two different reporter genes, HBsAg and luc. ${ }^{5}$

Hepatitis B virus (HBV) infection is endemic to many parts of the world and is one of the most important chronic virus infections, with over 300 million HBV carriers worldwide. $^{6}$ Infection is transmitted most commonly from chronically infected mothers to their newborns, who consequently often develop chronic hepatitis B. Many adults exposed to HBV suffer acute infections, a minority of which do not resolve but rather progress to chronic hepatitis B. ${ }^{7}$ Long-term sequelae of chronic hepatitis B include cirrhosis and hepatocellular

Correspondence: DS Strayer, Department of Pathology, Jefferson Medical College, 1020 Locust Street, Philadelphia, Pennsylvania 19107, USA Received 20 June 1997; accepted 11 December 1997 carcinoma, the latter being one of the most common cancers in the world.7,8

Since there is no effective treatment available for chronic hepatitis B, prevention is indispensable. Recombinant hepatitis $B$ vaccines were the first recombinant vaccines approved for human use. ${ }^{9}$ They were produced by subcloning the HBsAg gene into expression vectors that would direct the synthesis of large quantities of HBsAg in the host cells. The use of both yeast and mammalian host cells has been evaluated clinically. Approximately 20 to $25 \%$ of mammalian cell-derived HBsAg is glycosylated, while yeast-derived HBsAg is not. ${ }^{10}$ Both preparations elicit protective antibodies comparably, and the yeast-derived vaccine has been preferred. ${ }^{9}$ However, up to $10 \%$ of adults immunized against HBV still fail to respond to the currently used recombinant vaccines. ${ }^{11}$

HBsAg is also one of the most suitable markers to test the efficiency of an expression vector in mammalian cells. In vivo, HBsAg synthesis allows straightforward immunochemical detection of $\mathrm{HBsAg}$ gene expression in animals. HBsAg also elicits antibodies, permitting indirect demonstration of effective transduction by measuring antibody activity.

We examined the ability of the SV40-vector system to express a protein that would induce an immune response and as such, act as a vaccine. We report successful use of this gene delivery system to immunize mice against HBsAg. Significant levels of anti-HBs serum antibodies were found after the second inoculation. Importantly, we also found that the large $\mathrm{T}$ antigen (Tag)-deleted SV40- 
vector itself is not detectably immunogenic, even after eight inoculations.

\section{Results}

\section{SV(HBS)}

The principles used in the construction of Tag-deleted, replication-incompetent SV40 derivative viruses bearing transgenes such as hepatitis B surface antigen gene, SV(HBS), have been described. ${ }^{2}$ Methods used to construct and propagate SV(HBS), as well as the specifics of the HBsAg gene included, are described in Materials and methods. A map of the SV(HBS) genome is shown in Figure 1.

\section{Detection of HBsAg transcript in TC7 cells infected with $S V(H B S)$}

TC7 cells were infected with SV(HBS) and control cells were mock-infected. Total RNA was extracted from infected cells, electrophoresed, transferred to a nylon membrane, and hybridized with a cDNA probe for the $\mathrm{HBsAg}$ gene. Expression of HBsAg was detected in SV(HBS)-infected cells but not in mock-infected cells (Figure 2). Two transcripts were observed: a $1 \mathrm{~kb} \mathrm{HBsAg}$ transcript, plus a larger mRNA of $4.6 \mathrm{~kb}$. The latter most likely represents read-through transcription, which we often observe in this system. As control, the same blot was stripped and hybridized with a cDNA probe for GAPDH, which showed expression from both treatment groups (Figure 2).

Expression of HBsAg was confirmed by RT-PCR analysis. Total RNA was extracted from SV(HBS)-infected and SV(luc)-infected TC7 cells and used as a template for RTPCR. RT-PCR negative control was also performed without RNA template. The expected product of $438 \mathrm{bp}$ was identified only from the cell sample infected with

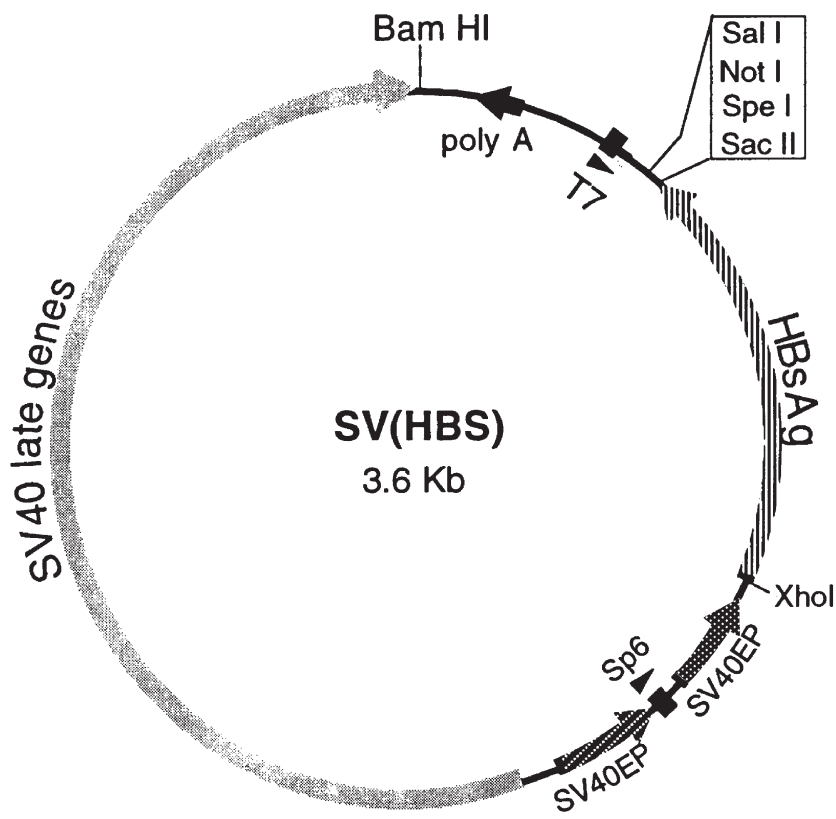

Figure 1 Map of $S V(H B S)$. This recombinant viral genome is excised from $p S V 5(H B S)$ as a NotI fragment, and then recircularized (see Materials and methods). It contains two head-to-tail SV40 EP followed by HBsAg gene and the SV40 polyadenylation signal.

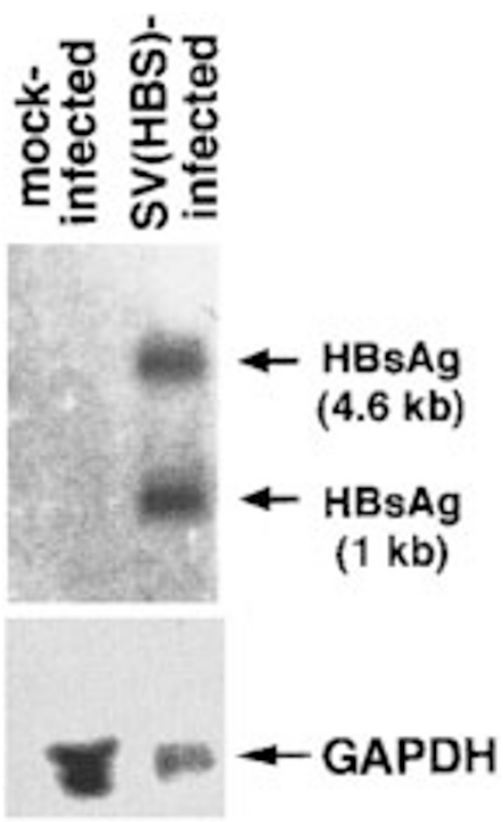

Figure 2 Expression of HBsAg gene in TC7 cells. TC7 cells were transduced with SV40 derivative virus containing HBsAg gene (SV(HBS)) at MOI of 10. Mock-infected cells were treated similarly in control preparation without the virus. RNA was harvested from these cultures, $24 \mathrm{~h}$ later, then electrophoresed, blotted and hybridized with HBsAg probe (see Materials and methods). The second HBsAg transcript represents a readthrough $m R N A$, as we have seen in many cases in this system. Its size is indicated. The same filter was stripped and reprobed with a control cDNA probe (GAPDH).

SV(HBS). It was not observed when RNA was pretreated with RNase before RT-PCR. RNA from TC7 cells infected with an unrelated SV40-derivative virus, SV(RGP) (see Materials and methods), was negative for HBsAg transcript (Figure 3).

\section{Detection of HBsAg in TC7 cells in vitro}

To determine whether detectable levels of HBsAg were produced in cultured cells on infection with SV(HBS), TC7 cells were infected at a MOI of 10 . Control cells were mock-infected. SV(HBS)-infected and mock-infected cells were harvested $24 \mathrm{~h}$ later. Cell lysates were electrophoresed, blotted, and treated with anti-HBs rabbit polyclonal antiserum, followed by HRP-conjugated goat anti-rabbit antibody. HBsAg was detected by chemiluminescence in SV(HBS)-infected cells but not in mock-infected cells (Figure 4). HBsAg was also detected by immunostaining as described elsewhere. ${ }^{5}$

The sizes of the HBsAg protein bands produced by infecting with SV(HBS) were slightly different from the sizes of the bands detected within recombinant HBsAg. These differences may reflect different post-translational modifications (eg glycosylation). The presence of multiple bands may reflect the tendency of different preparations of HBsAg that were prepared differently to undergo variable oligomerization.

\section{Detection of anti-HBs in mouse serum}

To determine whether the SV40-derived virus could produce HBsAg in vivo and therefore elicit detectable antiHBs in mice, BALB/cJ mice were treated in three groups of five mice each: intraperitoneal (i.p.) inoculation of $10^{8}$ 


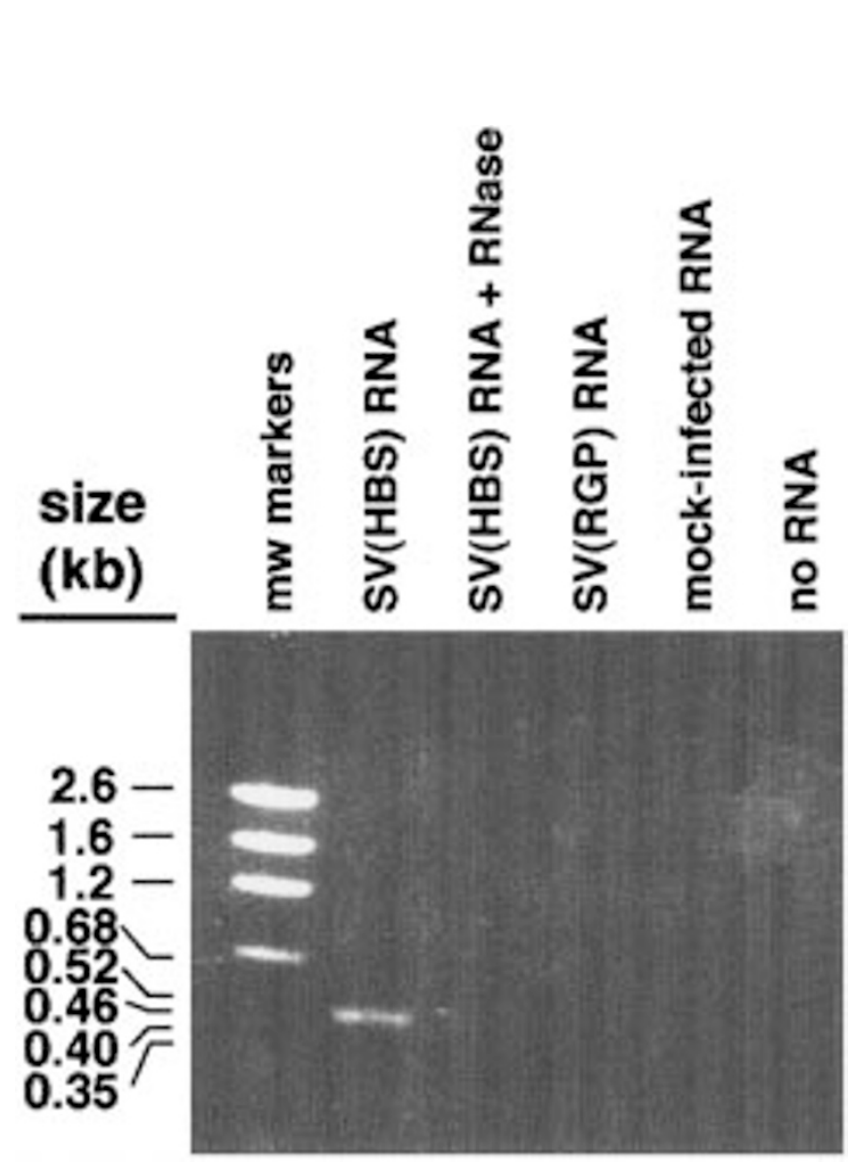

Figure 3 RT-PCR amplification of HBsAg transcript in TC7 cells. TC7 cells were transduced with SV(HBS) at a MOI of 10. Control cells were mock-infected or were infected with a different SV40-derived virus $(S V(R G P))$, containing the gene for the major glycoprotein of rabies virus, but lacking HBsAg. RNA was harvested from these cultures $24 \mathrm{~h}$ after infection. An aliquot of RNA from SV(HBS)-infected cells was treated with RNase before RT-PCR. RT-PCR was performed using primers within the HBsAg gene (see Materials and methods). RT-PCR negative control was performed without the RNA template. Molecular size markers ( $p$ GEM markers; Promega) are shown on the left.

IU per mouse, subcutaneous (s.c.) inoculation of $10^{8} \mathrm{IU}$ per mouse, and vehicle (DMEM/2\% FBS) only. Mice were bled every 2 weeks to collect sera. Inoculation was done after bleeding, every fourth week. Each serum sample was tested for antibody to HBsAg by ELISA. Levels of serum anti-HBs were increased significantly following the second injection, and remained elevated in both i.p.- and s.c.-injected mice (Figure 5).

The antibody, so produced was also characterized by Western blot analysis using commercially supplied HBsAg (Scantibodies Laboratories, Santee, CA, USA) (Figure 6).

In these blots, the murine antisera, as well as the rabbit antiserum, all recognized the $24 \mathrm{kDa}$ recombinant protein. Higher molecular size derivatives or oligomers present in this recombinant protein preparation were also recognized by the control rabbit antiserum but not by sera from the mice receiving SV(HBS).

\section{Neutralizing antibody vs SV4O is not detectable}

We tested the same sera to see whether SV40-derived virus itself was an effective antigen in vivo. SV(HBS) was incubated with the same murine sera that tested positively for anti-HBs, and then used to infect TC7 cells. The treated cells were tested for SV40 infection by in situ PCR.

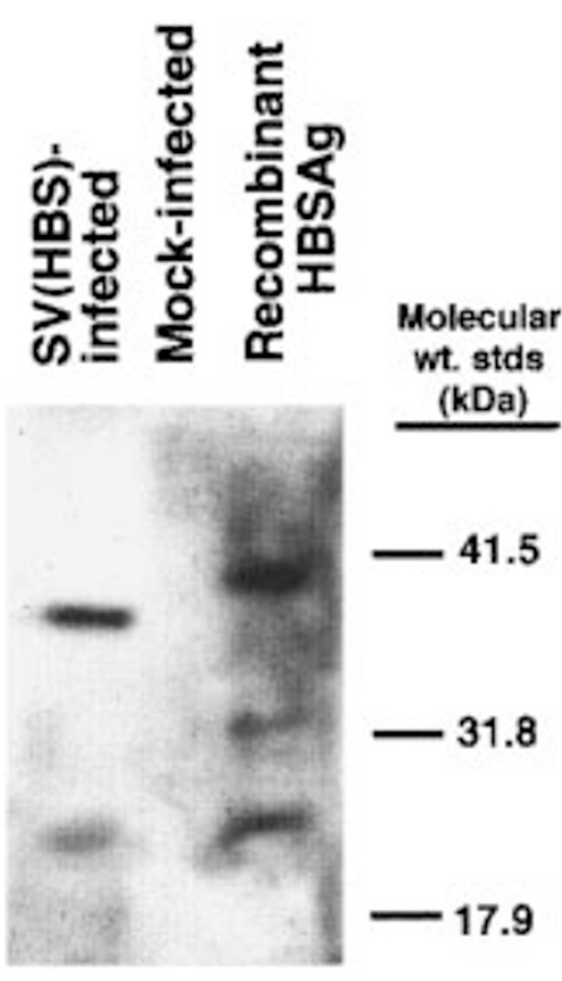

Figure 4 Expression of $\mathrm{HBs} A g$ in TC7 cells transduced with SV40 derivative virus containing HBsAg gene. SV(HBS) were used to transduce TC7 cells in vitro at a MOI of 10. Mock-infected cells were treated similarly in control preparation without the virus. Protein lysate was harvested from these cultures $24 \mathrm{~h}$ after infection (see Materials and methods). Sixty micrograms of cell lysate was electrophoresed by SDS-PAGE, blotted, then treated with anti-HBs rabbit polyclonal antibody followed by HRP conjugated goat anti-rabbit antibody. Signal was detected by chemiluminescence assay.

This assay, performed on microscope slides of virustreated cells, allows direct visualization and both reproducible and rapid enumeration of SV(HBS)-infected cells. Sera from i.p.- and s.c.-inoculated mice did not neutralize SV40 infectivity differently from prebleed sera, even after eight inoculations (Figure 7). Control recipient sera, similarly, failed to neutralize SV40 infectivity. Simultaneously, rabbit antiserum to SV40 (diluted 1:400, see Materials and methods) neutralized $>94 \%$ of virus infectivity, as our positive control. Pre- and post-inoculation sera from mice that received SVluc failed to neutralize SV(HBS) (not shown).

\section{Discussion}

Nonreplicating recombinant viruses have been generated for the purpose of vaccination, principally using poxviruses for veterinary applications. Most notably, vaccinia virus based-recombinant vaccines have been used against, for example, vesicular stomatitis, influenza, and rabies viruses. ${ }^{12-16}$ Additional poxviral vectors have also been used for immunization, including fowlpox, ${ }^{17-19}$ canarypox $^{20}$ capripox $^{21}$ and pigeonpox. ${ }^{22}$ In humans, canarypox-based vaccines expressing antigens from rabies virus ${ }^{23}$ and HIV $^{24,25}$ have been shown to be safe and immunogenic and other canarypox virus-based vaccines are being assessed.

Several recombinant vaccinia viruses have been con- 


\section{Inoculation group}

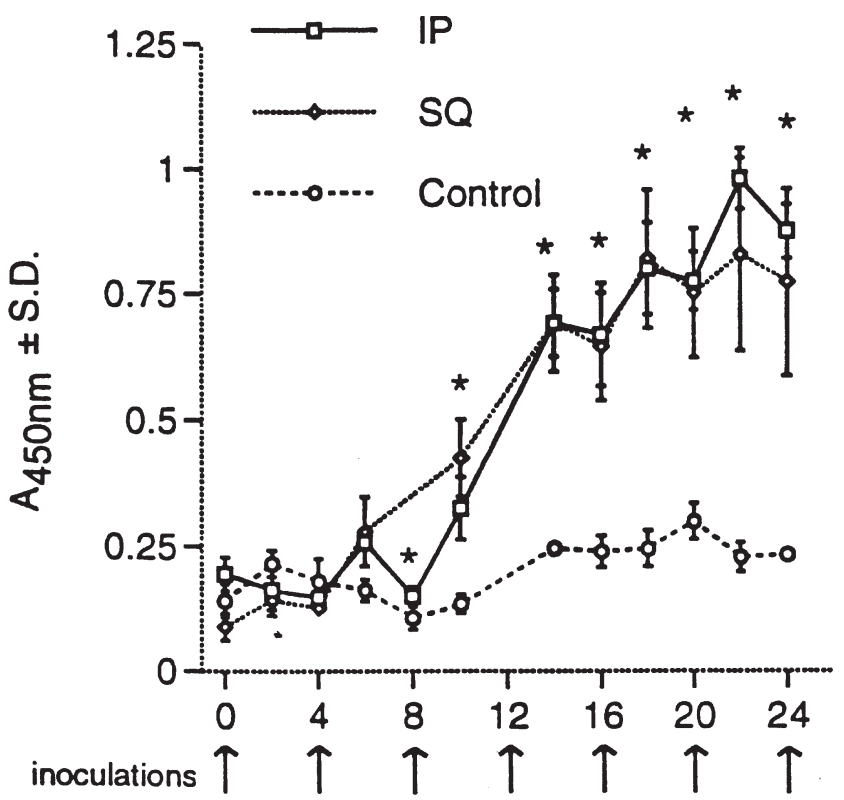

Time after initiation of inoculation schedule (weeks)

Figure 5 Production of antibody against HBsAg in mice. SV(HBS) $\left(10^{8}\right.$ IU) were used to inject mice every 4 weeks; five each of control, intraperitoneally and subcutaneously injected mice. These mice were bled every 2 weeks. Serum samples were diluted to 1:10 and antibody versus HBsAg were measured by ELISA assay (see Materials and methods). Individual serum samples were averaged for each treatment group and time point, \pm s.e.m. IP; intraperitoneal injection, SQ; subcutaneous injection. * $P<0.05$, compared with control sera drawn at the same time point. Arrows indicate when SV(HBS) or control injection occurred after bleeding.

structed that direct the synthesis of HBsAg in vivo. 26,27 Chimpanzees infected with vaccinia virus-HBV recombinant were protected against HBV challenge. ${ }^{28}$ Recombinant adenovirus also produced HBsAg in vitro ${ }^{13}$ and elicited anti-HBs in rabbits ${ }^{29}$ and hamsters. ${ }^{30}$

The HBV genome consists of a small (approximately $3.2 \mathrm{~kb}$ ), partially double-stranded, circular DNA molecule. ${ }^{31} \mathrm{HBsAg}$ is made up of a group of viral structural proteins that constitute the principal components of subviral particles, filaments and the viral envelope. ${ }^{25,31}$ The $\mathrm{HBsAg}$ gene is one of the four major open reading frames (ORF). It contains three in-frame translation initiation codons that divide the gene into three coding regions known as preS1, preS2 and S. The three polypeptides produced are known as the major (S), middle (preS2 + $S)$, and large (preS1 + preS2 $+\mathrm{S}$ ) proteins. The major $S$ protein is the most abundant form, and exists as a glycoprotein of $27 \mathrm{kDa}$ (GP27) and as a nonglycosylated $24 \mathrm{kDa}$ protein (P24). PreS1(P39/GP41) proteins and preS2 (GP33/GP36) proteins constitute approximately $2 \%$ and $15 \%$ of the HBsAg proteins produced from this ORF. ${ }^{10}$ Due to high cysteine content, these HBsAg proteins form mixed dimers or oligomers after dissociation with mercaptoethanol, which may yield complicated patterns and slower migration on SDS-PAGE. ${ }^{26}$ Repeated freezing and thawing can also cause spontaneous aggregation. This tendency to mixed oligomerization may

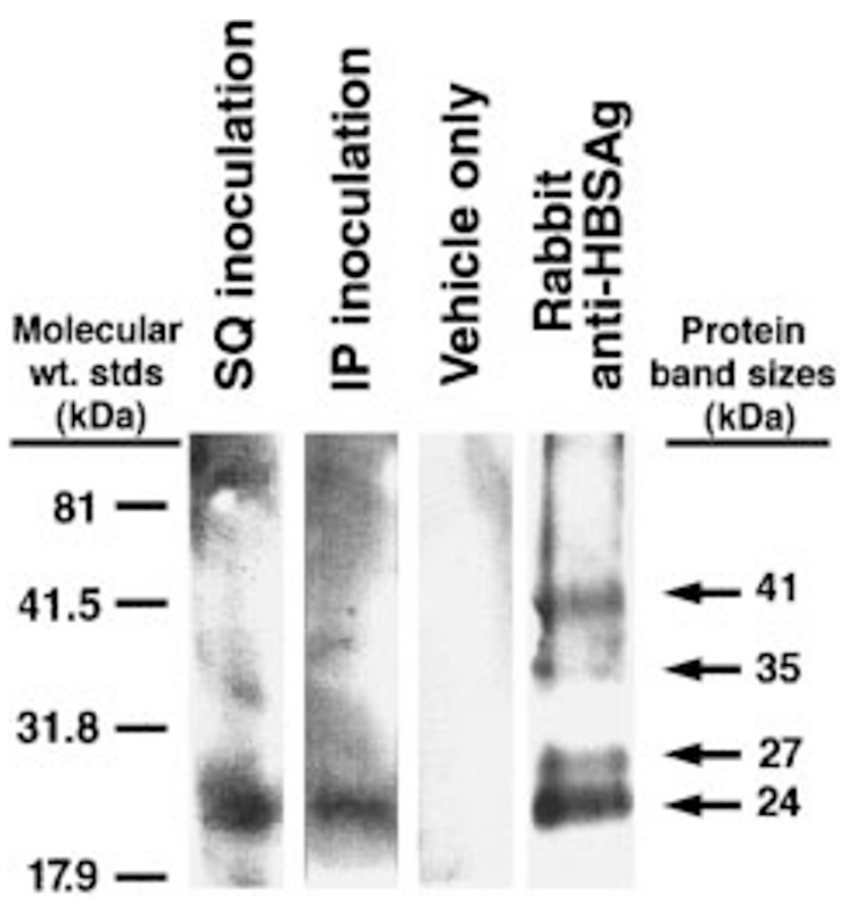

Figure 6 Characterization of antibody against $H B s A g$ elicited by SV(HBS). Commercial HBsAg was electrophoresed on SDS-PAGE gel and blotted. Membranes were hybridized to serum from mice inoculated with SV(HBS), and then to HRP-conjugated sheep anti-mouse Ig. Signal was detected by chemiluminescence assay. IP; intraperitoneal injection, $S Q$; subcutaneous injection.

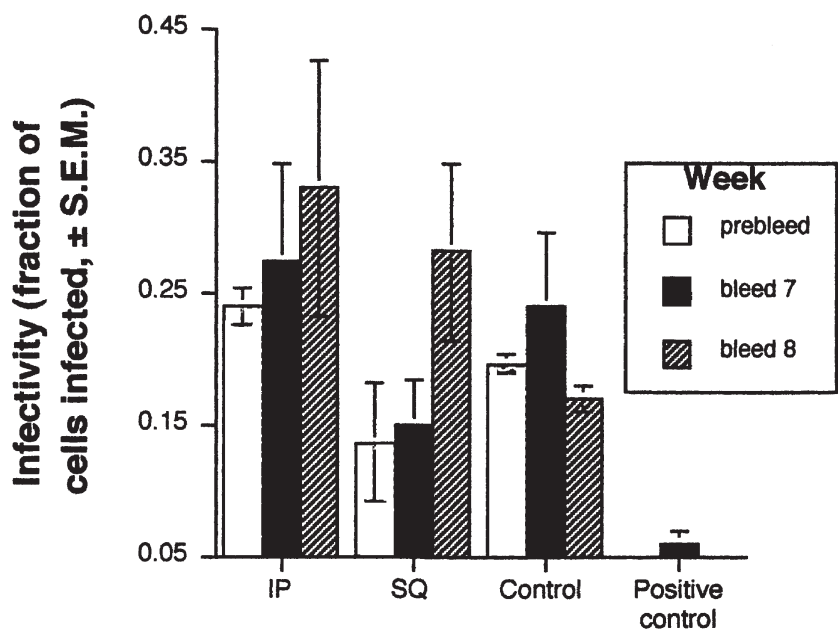

Inoculation group

Figure 7 Production of antibody against SV40 in mice. SV(HBS) was incubated with mice sera diluted to 1:100, before infection to TC7 cells. The proportions of TC7 cells infected was determined by in situ PCR (see Materials and methods). IP; intraperitoneal injection, SQ; subcutaneous injection. Within each group, the fraction of infected cells was not significantly different in comparing prebleed and post-inoculation samples. Rabbit anti-SV40 serum (kindly provided by Dr JS Butel) served as the positive control. This serum was tested at a 1:400 dilution, and the fraction of cells infected following treatment with this antiserum was significantly different $(P<0.01)$ from all other groups tested. 
account for the diverse banding patterns noted in our Western blots, including slower migration seen in some of our studies.

Different methods of preparation may be reflected both by different banding patterns seen when the same sera were used to probe HBsAg produced by TC7 cells and HBsAg produced by recombinant methods in bacteria (eg Figure 5). The fact that HBsAg delivered to eukaryotic cells may differ somewhat in structure from HBsAg derived from bacteria may also account for the differences in banding patterns seen when recombinant HBsAg is probed by our mouse antisera, compared to commercial rabbit antisera.

SV40 is a small $(5.2 \mathrm{~kb})$ nonenveloped double-stranded DNA virus of the papilloma virus group. A number of features of SV40 are advantageous for use as a gene transfer vehicle: (1) It infects and express its genes in cells from variety of tissues and of different animals. (2) Its genome may persist in infected cells, either by integration or as a minichromosome. ${ }^{4}$ (3) Live, wild-type SV40 was an unrecognized contaminant in early lots of polio vaccines, and was inadvertently administered to many polio vaccine recipients. However, extensive epidemiologic studies on polio vaccine recipients have not shown any significant adverse effect of live wild-type SV40 in humans. ${ }^{32,33}$ (4) In addition, as shown in the present work, the administered SV40 virus particle itself elicits no detectable neutralizing antibody response by itself. Animals in which the virus replicates may produce antibodies against these proteins. In the absence of virus replication, we did not detect antibodies capable of neutralizing the virus' infectivity.

SV40 encodes five major proteins, including three structural genes and large and small $\mathrm{T}$ antigens. ${ }^{34}$ The transforming property ${ }^{35}$ and the principal target of immunity vs SV40-infected cells is the large T antigen. ${ }^{36}$ $\mathrm{T}$ antigen is necessary for late virus gene expression and for virus DNA replication. However, we have found that $\mathrm{T}$ antigen-deficient SV40 can be grown easily to a relatively high titer ( $>10^{9}$ infectious units per milliliter) in COS cells, which supply the missing $\mathrm{T}$ antigen in trans. ${ }^{1,2}$ (5) The efficiency of transduction and level of expression are known to be very high. Thus, using HBsAg, we examined the use of this SV40 system for the introduction of genes in vitro and in vivo.

The purpose of these studies was to test the ability of SV40 to deliver DNAs encoding important antigens, such as HBsAg. Our data show that SV(HBS) elicited high levels of antibody against $\mathrm{HBsAg}$. Mice receiving a single inoculation did not induce detectable antibody within 4 weeks. While additional bleeds at later times may have allowed us to detect serologic immune responses, a second inoculation was performed 4 weeks after the first and it elicited detectable levels of antibody. Anti-HBs antibody activity in immunized mice remained above control and prebleed levels thereafter. Antibody activity increased with additional inoculations. We did not test cell-mediated immunity.

Our data show no evidence of neutralizing antibody against SV40. We used BALB/c mice, which have been shown to produce high levels of antibody when inoculated with wt SV40.37,38 Most antibody responsiveness against wt SV40, and the most studied antibody responses, are against Tag. ${ }^{39,40}$ Antibody activity against the structural proteins of SV40 is most readily measured by virus neutralization assays, similar to those done here. In some cases, wt SV40 and related papovaviruses have been reported to elicit neutralizing antibodies, usually at low levels. ${ }^{41}$ However, these responses are generally small in comparison to antibody responses to $\mathrm{Tag}^{42}$ and the extent to which antibody responses vs virus structural proteins may require virus replication and/or Tag expression is not clear.

We found no evidence of such antibodies in our studies. SV40 is not phagocytosed like other large particulates. Rather, the virus interacts with a cell membrane receptor, thought to be class I $\mathrm{MHC}^{43,44}$ to yield an endocytic vesicle that goes directly to the nucleus, where the virus uncoats. ${ }^{45}$ Antigen processing in phagolysosomes is not clearly documented for SV40. This observation, together with the lack of Tag and the consequent lack of late gene expression in infected cells, may account for the absence of detectable antibody responses to capsid antigens.

In considering the potential for Tag-deleted SV40 as a gene transfer vehicle, the most important operational issues to be resolved regarding immunogenicity center on the antigenicity of infected cells and the antigenicity of the inoculated virus particle. In the one case, immunogenicity of infected cells will limit the longevity of transgene expression in immunocompetent hosts. In the other, immune responses against the virus particle may restrict the potential for multiple inoculations. Our studies to date suggest that Tag-deficient SV40 may be useful as a gene transfer vehicle on both accounts.

\section{Materials and methods}

\section{Cell lines}

Two monkey cell lines were used: COS-7 cells (ATCC, Bethesda, MD, USA) which contain an origin-defective SV40 genome, and TC7 cells which do not. Both cell lines were maintained by serial passage in Dulbecco's modified Eagle's medium (DMEM)-10\% fetal bovine serum (FBS) (GIBCO, Grand Island, NY, USA).

\section{Mice}

Retired female bleeders, BALB/cJ (Jackson Laboratories, Bar Harbor, ME, USA), were fed and housed in accordance with American Association for Accreditation of Laboratory Animal Care standards.

\section{Generation of recombinant SV40}

The HBsAg gene was cloned into pSV5, which yielded pSV5(HBS). The details of the construction of this plasmid is described elsewhere. ${ }^{3}$ Briefly, pSV5 consists of the SV40 genome, minus the $\mathrm{T}$ antigen gene, plus a polylinker immediately downstream of two tandem SV40 early promoters (EP). This viral genome was cloned, using an engineered NotI site in the polylinker, into pGEM13. A 739 bp DNA fragment containing the coding sequences of the HBsAg major protein gene (see Discussion) was amplified by polymerase chain reaction (PCR) using oligonucleotide primers that contained orienting restriction sites; HBVS1 (5'-TTCTCGAGGAT TGGGGACCC-3') and HBVS2 (5'-GGACCGCGGCTC TTTGTTTTGTTA-3'). This HBsAg DNA encoded a 24 $\mathrm{kDa}$ protein of 226 amino acids.

The PCR product was digested with XhoI and SacII and 
subcloned directionally to the pSV5 polylinker. Recombinant SV40 derivative virus, SV(HBS), was produced by excising the recombinant virus genome from pSV5(HBS) with NotI, band-purifying it, then recircularizing the modified viral genome, and transfecting it into packaging cell line (COS-7 cells) (Figure 1). The anticipated transcript length for this transgene is $1 \mathrm{~kb}$, including the untranslated $3^{\prime}$ end of the HBsAg transcript which was joined to $0.2 \mathrm{~kb}$ of untranslated SV40 sequences before the polyadenylation signal. The entire SV(HBS) virus genome is $3.6 \mathrm{~kb}$.

Two weeks later, crude virus was obtained by three rounds of freezing-thawing the cells, followed by $2.5 \mathrm{~min}$ sonication. This lysate was used to produce working stocks of virus by infecting more COS-7 cells.

Infection, $2 \mathrm{~h}$ at room temperature, was done in a small volume of culture medium (DMEM/2\% FBS). After infection, more medium was added and cultures were incubated for 2 weeks at $37^{\circ} \mathrm{C}, 7 \% \mathrm{CO}_{2}$ until approximately $50 \%$ of cells were infected as judged by cytopathic effect. Virus was harvested by freezing-thawing and sonication, as described above.

SV(RGP) was used as a control virus in some of these studies. It lacks HBsAg. Instead, SV(RGP) contains the gene for the major glycoprotein antigen of rabies virus (a gift from Dr H Koprowski, Thomas Jefferson University, PA, USA), cloned downstream from the cytomegalovirus intermediate-early promoter. Production and expansion of SV(RGP) stocks was carried out similarly to that for SV(HBS). SVluc, an additional control virus used in some of our studies, contains the firefly luciferase transgene instead of HBsAg. Its production and characteristics have been published. ${ }^{2,3}$

\section{Measuring infectivity of SV(HBS) by in situ PCR}

Virus was titrated using TC7 cells, by in situ PCR, an approach we devised specifically to measure the infectivity of replication-incompetent DNA viruses. ${ }^{46}$ Appropriate dilutions of SV(HBS) in DMEM/2\% FBS were used to infect TC7 cells in $2.5-\mathrm{cm}$ wells. Each well was layered with $100 \mu \mathrm{l}$ of diluted virus stock and $400 \mu \mathrm{l}$ of DMEM $/ 2 \%$ FBS, and was incubated for $2 \mathrm{~h}$ at room temperature, shaking. More medium was added and cultures were incubated for $24 \mathrm{~h}$ more. Cells were trypsinized and placed on 3-amino-propyl-triethoxy-silane treated Teflon slides (Erie Scientific, Erie, PA, USA). Slides were fixed with $4 \%$ paraformaldehyde, then treated with proteinase $\mathrm{K}(6 \mu \mathrm{g} / \mathrm{ml})$. Each slide was covered with PCR cocktail $(250 \mathrm{~mm}$ each of $\mathrm{dNTP}, 1 \mu \mathrm{m}$ each of primer, $0.1 \mathrm{U} / \mu \mathrm{l}$ of Taq polymerase, $500 \mathrm{~mm} \mathrm{KCl}, 100 \mathrm{~mm}$ Tris $\mathrm{pH} 8.3,15 \mathrm{~mm}$ $\mathrm{MgCl}_{2}$ and $0.01 \%$ gelatin). The primers were BP3-1 (5'-ACTGTGACTGGTGTGAGCGCTG-3') and BP3-2 (5'-TGGACCCCAATGTCTGGGGTC-3'). The slide was covered with cover slips, sealed with nail polish, and incubated as follows: $94^{\circ} \mathrm{C}$ for $1 \mathrm{~min}, 50^{\circ} \mathrm{C}$ for $1.5 \mathrm{~min}$, and $72^{\circ} \mathrm{C}$ for $1 \mathrm{~min}$ for 35 cycles (PT-100; MJ Research, Watertown, MA, USA). After removing the coverslip, the slide was hybridized $(50 \%$ formamide, $2 \times$ SSC, $10 \times$ Denhardt's solution, $1 \mathrm{mg} / \mathrm{ml}$ salmon sperm DNA, $0.1 \%$ SDS, $32 \mathrm{~mm} 5^{\prime}$ biotinylated probe) overnight at $37^{\circ} \mathrm{C}$. The color of the slide was developed by incubation at $37^{\circ} \mathrm{C}$ with $330 \mathrm{mg} / \mathrm{ml}$ streptavidin-peroxidase and then with a reaction solution $(50 \mathrm{~mm}$ sodium acetate $\mathrm{pH} 5.0$, $0.15 \% \mathrm{H}_{2} \mathrm{O}_{2}$ and 5\% 3-amino-9-ethyl-carbazole (Sigma, St Louis, MO, USA).
Detection of HBsAg transcript by Northern analysis

TC7 cells were infected with SV(HBS) at MOI of 10. Twenty four hours later, total RNA was prepared from cultured cells (RNAzolB; Molecular Research Center, Cincinnati, OH, USA), and electrophoresed (10 $\mu \mathrm{g}$ per lane) in formaldehyde gels, blotted to nylon membrane (Amersham, Arlington Heights, IL, USA). XhoI to SacII HBsAg fragment was labeled with $\alpha^{32} \mathrm{P}-\mathrm{dCTP}$ (DuPont NEN) for DNA probe. The membrane was baked for $2 \mathrm{~h}$ at $80^{\circ} \mathrm{C}$, prehybridized and hybridized at $42^{\circ} \mathrm{C}$ (solutions include 50\% formamide, $0.1 \%$ SDS), and washed stringently (final wash: $0.1 \times \mathrm{SSC}, 0.1 \% \mathrm{SDS}, 50^{\circ} \mathrm{C}$ ). Binding of radiolabeled probes was visualized by autoradiography. ${ }^{47}$

\section{Detection of HBsAg transcript by RT-PCR}

Total RNA from cultured cells was obtained as above. PCR was done in $50 \mu \mathrm{l}$ containing $1 \mu \mathrm{g}$ of total RNA, 1 $\mu \mathrm{M}$ each of primers HBVS3 (5'-CTAGACTCGTGG TGGACTTC-3') and HBVS4 (5'-CACTAGTAAACT GAGCCAGG-3'), $0.1 \mathrm{U} / \mu \mathrm{l}$ each of AMV reverse transcriptase and Tfl DNA polymerase (Promega, Madison, WI, USA), $0.2 \mathrm{~mm}$ each of $\mathrm{dNTP}, 1 \mathrm{~mm} \mathrm{MgSO}_{4}$ and AMV/Tfl reaction buffer (Promega, Madison, WI, USA). It was incubated as follows: $45 \mathrm{~min}$ at $48^{\circ} \mathrm{C}, 2 \mathrm{~min}$ at $94^{\circ} \mathrm{C}$, followed by 40 cycles of $94^{\circ} \mathrm{C}$ for $30 \mathrm{~s}, 60^{\circ} \mathrm{C}$ for 1 $\min$, and $68^{\circ} \mathrm{C}$ for $1 \mathrm{~min}$.

\section{Detection of HBsAg protein by Western blot analysis}

Cells were lysed with lysis buffer $(100 \mathrm{~mm}$ Tris $\mathrm{pH} 8.0$ $100 \mathrm{~mm} \mathrm{NaCl}, 0.5 \%$ NP-40, $1 \mathrm{~mm}$ PMSF, $10 \mu \mathrm{g} / \mathrm{ml} \mathrm{leu-}$ peptin, $2 \mu \mathrm{g} / \mathrm{ml}$ aprotinin, $10 \mu \mathrm{g} / \mathrm{ml}$ pepstatin). Protein lysate was loaded on a $12 \%$ SDS-polyacrylamide gel, electrophoresed and blotted to a PVDF membrane (Schleicher and Schuell, Keene, NH, USA). The membrane was blocked with 5\% skim milk for $2 \mathrm{~h}$, treated with rabbit polyclonal anti-HBs (1:1000 in 1\% BSA/PBST; Accurate Chemical and Scientific, Westbury, NY, USA) overnight at $4^{\circ} \mathrm{C}$, and then with horseradish peroxidase (HRP)-conjugated goat anti-rabbit antibody (1:1000 dilution with 1\% BSA/PBST; Transduction Laboratories, Lexington, KY, USA) for $2 \mathrm{~h}$ at room temperature. Signal was detected with chemiluminescence reagent (DuPont NEN, Wilmington, DE, USA).

\section{Detection of anti-HBs by enzyme-linked immunosorbent assay (ELISA)}

Ninety-six-well plates were coated with $1 \mu \mathrm{g}$ per well synthetic peptides (surface antigen peptide 28 ) $^{48}$ in PBS/10\% FBS. Fifty microliters of diluted serum samples (1:10 in PBS $/ 10 \%$ FBS) were transferred into corresponding wells for overnight incubation at $4^{\circ} \mathrm{C}$. Each well was washed six times with PBS, treated with HRP-conjugated goat anti-mouse Ig (1:1000 dilution). The plates were incubated for $1 \mathrm{~h}$ at $37^{\circ} \mathrm{C}$, washed six times in PBS and then substrate $(1.5 \mathrm{mg} / \mathrm{ml} \mathrm{o}$-phenylenediamine dihydrochloride in $0.05 \mathrm{~m}$ phosphate-citrate $/ 0.014 \% \quad \mathrm{H}_{2} \mathrm{O}_{2}$ ) added. Spectrophotometric readings at $450 \mathrm{~nm}$ were taken after $15 \mathrm{~min}$ of color development (Dynatech MR5000 ELISA plate reader, Alexandria, VA, USA).

\section{Detection of anti-HBs by Western blot analysis}

The above protocol for Western blotting was applied. Purified HBsAg protein $(0.4 \mu \mathrm{g})$ (Scantibodies Laboratories) per lane was electrophoresed (SDS-12\% 
PAGE) and blotted to PVDF membrane (Schleicher and Schuell), treated with test mouse serum (1:50 in $1 \%$ BSA/PBST) and then to HRP-conjugated sheep antimouse antibody (1:5000 in 1\% BSA/PBST; Amersham). Signal was detected with chemiluminescence reagent (DuPont NEN).

\section{Testing for neutralizing activity versus recombinant SV40 by in situ PCR}

One microliter of SV(HBS) $\left(10^{9} \mathrm{IU} / \mathrm{ml}\right)$ was incubated with $99 \mu \mathrm{l}$ of each mouse serum (1:100 dilution in $\mathrm{DMEM} / 2 \% \mathrm{FBS}$ ) for $2 \mathrm{~h}$ at $37^{\circ} \mathrm{C}$. This was added to TC7 cells in a $60 \mathrm{~mm}$ dish containing $400 \mu \mathrm{l}$ of DMEM/2\% FBS for in situ PCR (described above) to deduce the proportion of infected TC7 cells.

\section{Anti-SV40 serum}

Rabbit anti-SV40 serum was the kind gift of Dr J Butel (Baylor College of Medicine). It is capable of neutralizing $>50 \%$ of wt SV40 plaque forming activity at dilutions $>1: 400$, the dilution used in our virus neutralization assay.

\section{Acknowledgements}

The technical help and advice of Joseph Milano, Lisa E Bobrowski, and Marcia Clayton is gratefully acknowledged. In addition, the authors thank Drs Omar Bagasra, Hilary Koprowski and Kazuhisa Tsukamoto for encouragement and advice. Dr Ling-Xun Duan (Jefferson Medical College) kindly supplied us with a plasmid pHBV containing the HBsAg gene. TC7 cells and rabbit antiSV40 serum were generous gifts of Dr Janet S Butel (Baylor College of Medicine). This work was supported by grant CA44800 from the USPHS.

\section{References}

1 Strayer DS. Novel vectors for gene therapy. Adv Drug Deliv Rev 1995; 17: 235-238.

2 Strayer DS. SV40 as an effective gene transfer vector in vivo. J Biol Chem 1996; 271: 24741-24746.

3 Strayer DS, Milano J. SV40 mediates stable gene transfer in vivo. Gene Therapy 1996; 3: 581-587.

4 Chia W, Rigby PW. Fate of viral DNA in nonpermissive cells infected with simian virus 40. Proc Natl Acad Sci USA 1981; 78: 6638-6642.

5 Strayer DS, Kondo R, Milano J, Duan L-X. Use of SV40-based vectors to transduce foreign genes to normal human peripheral blood mononuclear cells. Gene Therapy 1997; 4: 219-225.

6 Yoffe B, Noonan CA. Hepatitis B virus: new and evolving issues. Dig Dis Sci 1992; 37: 1-9.

7 Buendia MA. Hepatitis B viruses and hepatocellular carcinoma. Adv Cancer Res 1992; 59: 167-226.

8 Beasley RP. The major etiology of hepatocellular carcinoma. Cancer 1988; 61: 1942-1956.

9 Ellis RW, Kniskem DJ. Recombinant hepatitis B vaccines. In: McLachlan A (ed). Molecular Biology of the Hepatitis B Virus. CRC Press: Boca Raton, FL, 1991, pp 307-322.

10 Heermann $\mathrm{K}-\mathrm{H}$ et al. Large surface proteins of hepatitis B virus containing the pre-S sequence. J Virol 1984; 52: 396-402.

11 Kruskall MS et al. The immune response to hepatitis B vaccine in humans: inheritance patterns in families. J Exp Med 1992; 175: 495-502.

12 Mackett M, Yilma T, Rose JK, Moss B. Vaccinia virus recombinants; expression of VSV genes and protective immunization of mice and cattle. Science 1985; 227: 433-435.
13 Davis AR et al. Expression of hepatitis B surface antigen with a recombinant adenovirus. Proc Natl Acad Sci USA 1985; 82: 7560-7564.

14 Blancou $\mathrm{J}$ et al. Oral vaccination of the fox against rabies using a live recombinant vaccinia virus. Nature 1986; 322: 373-375.

15 Wiktor TJ et al. Protection from rabies by a vaccinia virus recombinant containing the rabies virus glycoprotein gene. Proc Natl Acad Sci USA 1984; 81: 7194-7198.

16 Brochier B et al. Large-scale eradication of rabies using recombinant vaccinia-rabies vaccine. Nature 1991; 354: 520-522.

17 Boursnell ME et al. A recombinant fowlpox virus expressing the (NDV) protects chickens against challenge by NDV. Virology 1990; 178: 297-300.

18 Bayliss CD et al. A recombinant fowlpox disease virus that expresses the VP2 antigen of infectious bursal disease virus induces protection against mortality caused by the virus. Arch Virol 1991; 120: 193-205.

19 Elbauer $\mathrm{C}$ et al. Protection of chickens with a recombinant fowlpox virus expressing the Newcastle disease virus hemagglutinin-neuraminidase. Virology 1990; 179: 901-904.

20 Taylor $\mathrm{J}$ et al. Efficacy studies on a canarypox-rabies recombinant virus. Vaccine 1991; 9: 190-193.

21 Romero $\mathrm{CH}$ et al. Recombinant canarypox virus expressing the haemagglutinin protein gene of rinderpest virus: protection against rinderpest and lumpy skin disease viruses. Virology 1994; 204: 425-429.

22 Leveler C, Burny A, Meulemans G. Construction of pigenpox virus recombinant; expression of the Newcastle disease virus NDV fusion glycoprotein and protection of chickens against NDV challenge. Arch Virol 1991; 120: 193-205.

$23 \mathrm{Cadoz} \mathrm{M}$ et al. Immunization with canarypox virus expressing rabies glycoprotein. Lancet 1992; 339: 1429-1432.

24 Egan MA et al. Induction of human immunodeficiency virus type I (HIV-I)-specific cytotoxic T lymphocyte responses in seronegative adult by a non-replicating host-range-restricted canarypox vector ALVAC carrying the HIV-IMN env gene. J Infect Dis 1995; 171: 1623-1627.

25 Heermann K-H, Gerlich WH. Surface proteins of hepatitis B viruses. In: McLachlan A (ed). Molecular Biology of the Hepatitis B Virus. CRC Press: Boca Raton, FL, 1991, pp 109-144.

26 Cheng K-C, Smith GL, Moss B. Hepatitis B virus large surface protein is not secreted but is immunogenic when selectively expressed by recombinant vaccinia virus. J Virol 1986; 60: 337-344.

27 Watanabe K et al. Improved recombinant LC16m0 or LC16m8 vaccinia virus successfully expressing hepatitis B surface antigen. Vaccine 1989; 7: 53-59.

28 Lubek MD et al. Immunogenicity and efficacy testing in chimpanzees of an oral hepatitis B vaccine based on live recombinant adenovirus. Proc Natl Acad Sci USA 1989; 86: 6763-6767.

29 Ballay A et al. In vitro and in vivo synthesis of the hepatitis B virus surface antigen and of the receptor for polymerized human serum albumin from recombinant human adenoviruses. EMBO J 1985; 4: $3861-3865$

30 Morin JE et al. Recombinant adenovirus induces antibody response to hepatitis B virus surface antigen in hamsters. Proc Natl Acad Sci USA 1987; 84: 4626-4630.

31 Raney AK, McLachlan A. The biology of hepatitis B virus. In: McLachlan A (ed). Molecular Biology of the Hepatitis B Virus. CRC Press: Boca Raton, FL, 1991, pp 1-38.

32 Mortimer EA jr et al. Long-term follow-up of persons inadvertently inoculated with SV40 as neonates. New Engl J Med 1981; 305: 1517-1518

33 Shah K, Nathanson N. Human exposure to SV40: review and comment. J Epidemiol 1976; 103: 1-12.

34 Eckhart W. Polymavirinae and their replication. In: Fields BN et al (eds). Virology. Raven Press: New York, 1990, pp 1593-1607.

35 Bryan TM, Raddel RR. SV40-induced immortalization of human cells. Crit Rev Oncogen 1994; 5: 331-357.

36 Butel JS, Jarvis DL. The plasma-membrane-associated form of SV40 large tumor antigen: biochemical and biological properties. Biochem Biophys Acta 1986; 865: 171-195. 
37 Law LW, Takemoto KK, Rogers MJ, Ting RC. Induction of simian virus 40 (SV40) transplantation immunity in mice by SV40-transformed cells of various species. J Natl Cancer Inst 1977; 59: 1523-1526.

38 Cicurel L, Croce CM. Antibody response to simian virus 40 tumor antigen in nude mice reconstituted with T cells. J Immunol 1977; 119: 850-854.

39 Tevethia S. Characterization of hamster antibody reacting with papovavirus SV40 tumor antigen. J Immunol 1967; 98: 1257-1264.

40 Crawford LV, Pim DC, Lane DP. An immunochemical investigation of SV40 T-antigens. 2. Quantitation of antigens and antibody activities. Virology 1980; 100: 314-325.

41 Brown P, Tsai T, Gajdusek DC. Seroepidemiology of human papovaviruses. Discovery of virgin populations and some unusual patterns of antibody prevalence among remote peoples of the world. Am J Epidemiol 1975; 102: 331-340.

42 Stitt DT, Carroll RB, Melero JA, Mangel WF. Analysis of 84K, 55K and $48 \mathrm{~K}$ proteins immunoprecipitable by SV40 T antibody from SV40-infected and -transformed cells by tryptic peptide mapping on cation-exchange columns. Virology 1981; 111: 283-288.
43 Atwood WJ, Norkin LC. Class I major histocompatibility proteins as cell surface receptors for simian virus $40 . J$ Virol 1989; 63 : 4474-4477.

44 Breau WC, Atwood WJ, Norkin LC. Class I major histocompatibility proteins are an essential component of the simian virus 40 receptor. J Virol 1992; 66: 2037-2045.

45 Strayer DS et al. Titering replication-defective virus for use in gene transfer. BioTechniques 1997; 22: 447-450.

46 Hummeler K, Tomassini N, Sokol F. Morphological aspects of the uptake of simian virus 40 by permissive cells. J Virol 1970; 6 : 87-93.

47 Sambrook J, Fritsch EF, Maniatis T. Molecular Cloning, a Laboratory Manual. Cold Spring Harbor Laboratory Press: Cold Spring Harbor, NY, 1989.

48 Lerner RA et al. Chemically synthesized peptides predicted from the nucleotide sequence of the hepatitis B virus genome elicit antibodies reactive with the native envelope protein of Dane particles. Proc Natl Acad Sci USA 1981; 78: 3403-3407. 